\title{
Attachment of Liquid Cooling System and Air Pre Heater in Two Wheeler
}

\author{
Budarapu Pranav \\ Dept of Mechanical Engineering, \\ Sreenidhi Institute of Science and Technology, \\ Hyderabad, Telangana, India.
}

\author{
Parmati Sai Kiran \\ Dept of Mechanical Engineering, \\ Sreenidhi Institute of Science and Technology, \\ Hyderabad, Telangana, India.
}

\begin{abstract}
In this modern generation the usability of automobiles in every sector has a key role for transporting from one place to other, but the efficiency of those automobiles are not much good for the procurement majorly two wheelers are affordably used by the people for fullfillimg their needs, but the efficiency of the two wheelers may not be a satisfactory factor to the consumers in order to satisfy the customers in the era of efficiency as well as engine life span, we made an advancement to the two wheeler ( ROYAL ENFIELD CLASSIC 350 CC) to increase the efficiency and the life span i.e.., we made an attachment of liquid cooling system to the engine for direct cooling and a air pre heater to increase the mechanical efficiency of the two wheeler.
\end{abstract}

\section{INTRODUCTION}

Now a days the people are more prominent in saving the time to improve them selves, but there is big problem for transportation from one place to other by road the number of people coming out are increasing day to day, as the people are favourbly using their own automobiles for transportation like cars, bikes, scooty etc .. mostly two wheelers are affordably used in order to move quickly because the space required for the two wheelers are less compared to cars buses etc.., but the people are not much satisfactory about the efficiency of the automobiles due to some traffic and road issues the milage offered by the two wheelers are may not satisfiying the people, in order to satisfy the people we made an advancement to the two wheeler automobile engine, as we choosen (ROYAL ENFIELD CLASSIC 350) we made an attachment of liquid cooling directly to the engine for more effective cooling of the engine and also we added an another feature AIR PRE HEATER where the air is pre heated by the coolant passed through the engine so that the air entering into the engine is raises it's temparature by the liquid coolant it self so that by attachment of a single equipment we are probably getting twowengefitscooling the engine far better than air cooling system with a greater performance

2. We are increasing the milage of the two wheeler so that for the same amount of fuel the bike produces more milage

BLOCK DIAGRAM OF ATTACHMENTS FOR TWO WHEELER:

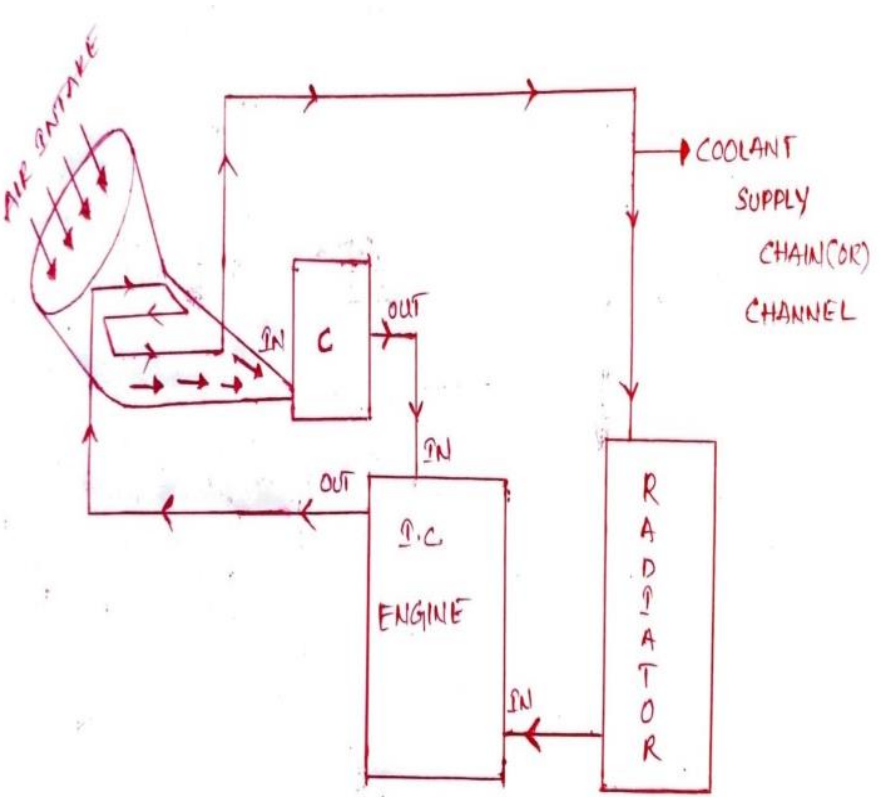

2. BRIEF DESCRIPTION ABOUT THE ATTACHMENT OF LIQUID COOLING SYSTEM AND AIR PRE HEATER

Normally a bike consists of an IC engine where it produces mechanical energy by the process under going combustion of fuel inside the engine cylinder so that the energy generated inside the engine cylinder is converted to mechanical energy for tha advancement of the bike, as the cumbustion process is taking place inside the engine cylinder continuously the amount of heat generated is greater than the required amount of heat, as we know that the heat more than the required stage is not at all usable, that was exhausted by the exhaust pipe to the atmosphere but some amount of the heat is absorbed by the engine cylinder , cylinder body , piston etc.. due to this rapid generation of energy most of the energy is absorbed by the engine cylinder and further the fins and those are exposed to the atmosphere and the atmospheric air cools the fins and the excess heat is expelled or sent away by the fins.

But, it was applicable for upto certain limit the efficiency of the engine decreases due to the excess heat absorbed by the engine.

Now, we are made an attacment of liquid cooling system to the engine by producing some values around the engine body so that the coolant passes directly around the engine cylinder and it absorbs the maximum amount of excess heat produced by the engine i.e.., the engine cylinder produces nearly $2300^{\circ}-2500^{\circ} \mathrm{c}$ and it should be cooled up 
to $100^{\circ}-150^{\circ} \mathrm{c}$ that was absolutely cleared with liquid cooling system.

The liquid coolant which absorbs the heat from the engine is passed from engine to the air intake value by a passae of pipe in it so that the air which flows in contact with the pipe having liquid coolant with a greater temparature, then the temparature of the air inside the air tube will rises so that pre heated air enters into the carburettor, due to this the air is initially heated before entering into the carburettor this pre heated air takes low amount of fuel to produce air fuel mixture due to this the amount of fuel required for the cycle will become less so that the number of cycles per litre will increases due to this the milage of the vehicle

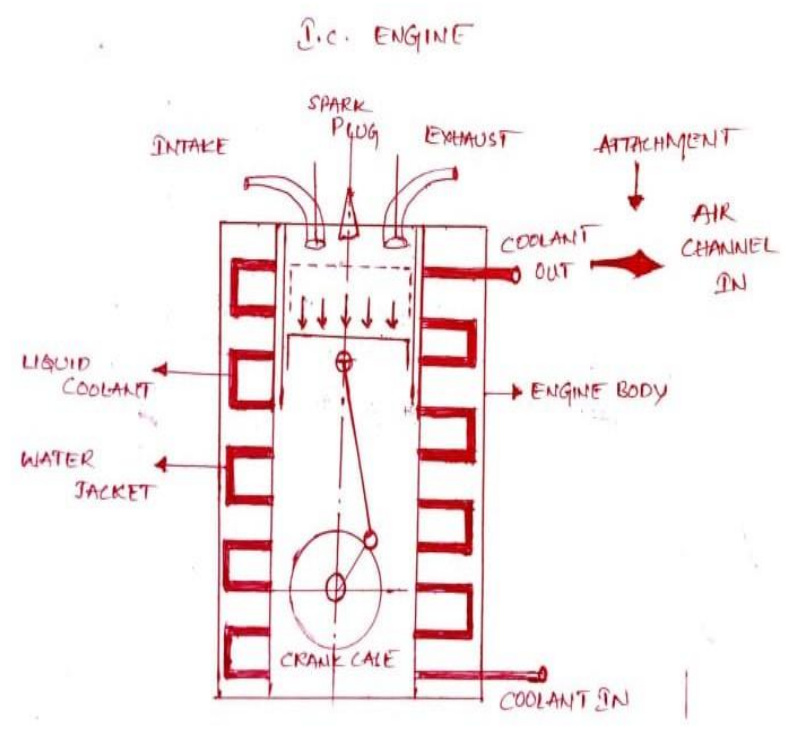

HERE, the fig describes the passage of liquid coolant passing through the engine for the removal of heat, and the fig representing outlet of the coolant from engine moves to the air intake channel for raising the temp of intake air by unwanted heat absorbed by the coolant.

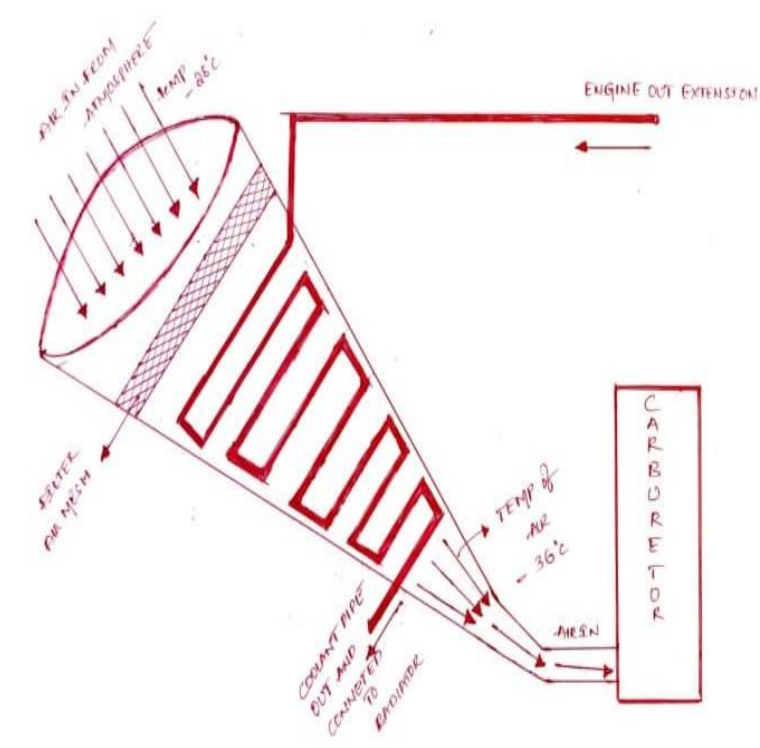

This fig describes that the coolant rises the temperature of inlet air and the coolant flow out to the radiator for further cooling to runthe cycle.

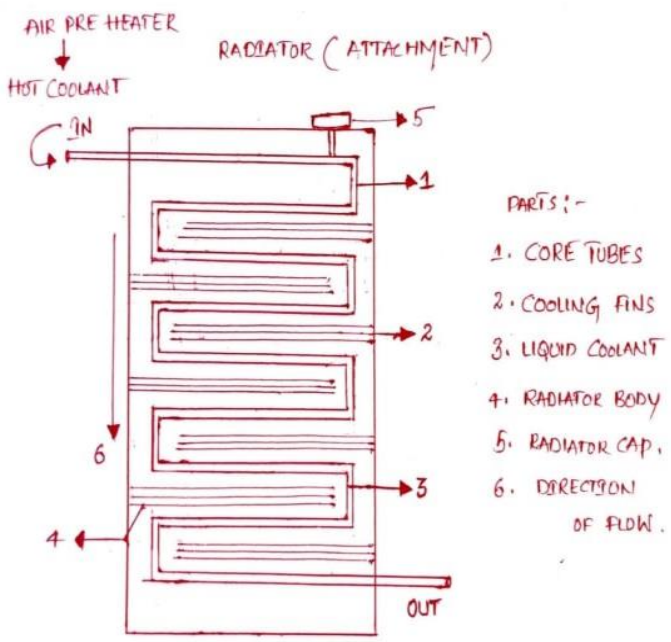

Here we absorbs that the coolant coming out from the air pre heatee section enter in to the radiator for further cooling for the next cycle.

\section{WORKING PRINCIPLE}

In the above paragraph it is stated that the energy is generated by the heat energy which is produced by the combustion of air fuel mixture in the engine cylinder and the energy generated by the cylinder has a greater temparature of nearly $2300^{\circ}-2500^{\circ} \mathrm{c}$ so those higher temperatures are of to be cooled down to $200^{\circ} \mathrm{c}$, in order to cool down from a greater temparature to a lower temperature we are arranging liquid cooling system to the engine where this system goes direct contact to the engine 
hence the fixed liquid coolant moves from radiator to the engine values and the higher temperatures are absorbed by the coolant due to this the temp of coolant raises by absorbing cylinders temparature and this temparatured coolant, normally goes to the radiatior to cool down but , we are extending the heat coolant flow to the air intake pipe with a zig Zag shaped tube of coolant into the larger air passage tube so that the air eentering into the vehicle in the channel gets contact with the hot coolant tube due to this the heat around the tube transfers to the air so that the air flowing in the channel get raises it's temparature from atmosphere temperature to a greater temparature due to this the air fuel mixture mixes fuel with a low amount with a temparatured air sure to this the mechanical efficiency of the vehicle increases, then the coolant is sent back to the radiatior for further cooling of the coolant and the process to be cycled.

\section{4 .WORKING OF LIQUID COOLING SYSTEM}

In general the liquid cooling system are mostly used for the removal of higher excess amount of heat produced by the engine so, we are implementing this system to the two the two wheeler for the increment of life of the engine majorly the life of a common two wheeler vehicle has a life span of 2 - 5 years where every care is taken place, if not it may reduced it to $1-3$ years as we implemented a liquid cooling system to the engine the risk taken by the engine is transferred to the cooling system so that the engine is free from risk after attachment of cooling system so that the engine works for more life time ie.., 4 - 6 years so that the people are more satisfactory for the product they purchased for full filling their needs

The coolant inside the system circulates around the engine cylinder to absorb the excess heat so that the engine will be in its required condition so that it works smooth and fine.

\section{CALCULATIONS}

Amount of heat dissipated by the engine using liquid cooling system:

$\mathrm{Q}=$ heat rejected $(\mathrm{KW})$

$\mathrm{Q}=\mathrm{MCp}(\mathrm{T} 2-\mathrm{T}$ !)

Mass flow rate $=\mathrm{A}^{*} \mathrm{~V}$

Flow of air $=2 \mathrm{~m} / \mathrm{s}$

Flow of coolant $=31 / \mathrm{min}$

Area $(\mathrm{A})=A=\pi r^{2}$

Here diameter $=20 \mathrm{~mm}$

There fore the mass flow rate $=1250 \mathrm{kh} / \mathrm{hr}$

$$
=0.3472 \mathrm{~kg} / \mathrm{sec}
$$

Hot water inlet temperature $=325 \mathrm{k}$

Hot water outlet temperature $=390 \mathrm{k}$

$\mathrm{Q}=\mathrm{M}^{*} \mathrm{Cp} *(390-325)$

$\mathrm{Q}=0.3472 * 2.518 *(65)$

$\mathrm{Q}=56.82 \mathrm{KW}$ isrejected by using liquid cooling system as we absorbed that the amount of heat dissipated by the engine using liquid cooling systemis far better than air cooled engines.

Now, we are calculating the efficiency by raisng the temperature of inlet air by using air pre heater,

Earlier we discussed that the coolasnt pipe uid extended to the air intake channel so that the coolant passes through the channel due to this air gets contact with it and the temperature raises.

1. BEFORE ATTACHMENT OF AIR PRE HEATER

The number of kilometers $/$ liter $=36 \mathrm{~km} /$ lit $(\mathrm{avg})$

Number of kilometers $/$ day $=50 \mathrm{~km}($ avg)

Distance travelled $/$ week $=350 \mathrm{~km}$

Number of liters fuel consumed $/$ liter $=350 / 36=9.72$ lit

Cost of petrol for 1 liter $=80$ rupees

Cost of petrol for a week $=9.72 * 80=778$ rupees

In an average the cost of travelling $50 \mathrm{~km}$ per day for a week took 778 ruppes of fuel

\section{AFTER ATTACHMENT OF AIR PRE HEATER}

Number of kilometers/ liter $=42 \mathrm{~km}$

Number of kilometers/ day $=50 \mathrm{~km}$

Distance travelled for a week $=350 \mathrm{~km}(\mathrm{avg})$

No of liters fuel consumed per week $=350 / 42=8.34$ liters

Cost of petrol for 1 liter $=80$ rupees

Cost of fueel for 8.34 liters $=667$ rupees

On an avg transport of $50 \mathrm{~km}$ per a day takes 667 rupees of fuel for a week

NOTE

After the attachment to the vehicle it takes 667 rupees and before it took 778 rupees for the same transport of a week Amount of rupees saved after attachment $=778-667=111$ rupees

It saves 111 rupees for a week and 444 rupees for a month .

$$
6 \text {. RESULT }
$$

After attachment of cooling system and air pre heater to the two wheeler the mechanical efficiency as well as the life span of the engine increases, as the cooling system decreases the maximum amount of heat from the engine to the atmosphere as that excesses heat is utilised by us to increase the temparature of the air taking inside the engine due to this the temparature of the intake air rises so that the milage of the two wheeler increases this parameter helps a lot for the people who are utilising the vehicle more for travelling .

Hence, we made two parameters new by a single attachment is cooling system

That cooling system cools the engine heavily and rrises the temparature of the intake air.

\section{REFERENCES}

[1] HEAT AND MASS TRANSFER S.C.AROA \& DOMKUNDWAR

[2] ENGINEERING HEAT TRANSFER C.P.GUPTA \& RAJENDRA PRAKASH

[3] AUTOMOTIVE MECHANICS WILLIAM H.CROUSE \& DONALD L.ANGLIN

[4] INTERNAL COMBUSTION ENGINES V.L MALEEV HEAT TRANSFER DATA BOOK C.P.KOTHANDARAMAN \& SUBRAMANIYAN 